\title{
Comparison between Fast Fourier Transform and Autoregressive Model on Analysis of Autonomic Nervous Function after Food Intake in Women
}

\author{
Kumiko Ohara1,2, Yoshimitsu Okita ${ }^{3}$, Katsuyasu Kouda ${ }^{4}$, Harunobu Nakamura ${ }^{{ }^{*}}$ \\ ${ }^{1}$ Graduate School of Human Development and Environment, Kobe University, Kobe, Japan \\ ${ }^{2}$ Japan Society for the Promotion of Science, Tokyo, Japan \\ ${ }^{3}$ Graduate School of Engineering, Shizuoka University, Hamamatsu, Japan \\ ${ }^{4}$ Department of Public Health, Kinki University Faculty of Medicine, Osaka-Sayama, Japan \\ Email: "hal@kobe-u.ac.jp
}

Received 3 February 2016; accepted 19 April 2016; published 22 April 2016

Copyright (C) 2016 by authors and Scientific Research Publishing Inc.

This work is licensed under the Creative Commons Attribution International License (CC BY). http://creativecommons.org/licenses/by/4.0/

(c) (i) Open Access

\section{Abstract}

Purpose: Heart rate variability (HRV) is acknowledged as a useful tool to estimate autonomic function. Fast Fourier transform (FFT) and autoregressive model (AR) are used for power spectral analysis of HRV. However, there is little evidence of agreement between FFT and AR in relation to HRV following food intake in females. In the present study, we applied both FFT and AR after food intake during the follicular and luteal phases, and compared raw low-frequency (LF) and highfrequency (HF) powers, and LF/HF ratio obtained with the two power-spectral analytical methods. Methods: All subjects participated in two sessions: follicular phase session and luteal phase session. In each session, R-R intervals were continuously recorded before and after meals, and power spectral analysis of heart rate variability was performed. We analyzed low-frequency power (LF: $0.04-0.15 \mathrm{~Hz}$ ) and high-frequency power (HF: $0.15-0.40 \mathrm{~Hz}$ ) by using FFT and AR. LF and HF power were computed for each $30 \mathrm{sec}, 1 \mathrm{~min}, 2.5 \mathrm{~min}$, and $5 \mathrm{~min}$ of the $5-\mathrm{min}$ R-R data before meal intake and at 20, 40, 60 and 80 min after meal intake. The LF/HF ratio was calculated as an index of sympathovagal balance. Results: In the present study, after $30 \mathrm{sec}$ and $1 \mathrm{~min}$ of segment analysis, there was little interchangeability between AR and FFT in LF, HF, and LF/HF ratio in both follicular and luteal phases. In $2.5 \mathrm{~min}$ or $5 \mathrm{~min}$ of segment analysis, there was interchangeability between FFT and AR in LF and HF, but not in the LF/HF ratio in both follicular and luteal phases. Additionally, FFT underestimated HRV compared with AR, and the extent of underestimation increased with increasing AR value. Conclusion: FFT underestimated HRV compared with AR, and FFT correlated poorly with AR when the analysis segment was shortened.

\footnotetext{
${ }^{*}$ Corresponding author.
}

How to cite this paper: Ohara, K., Okita, Y., Kouda, K. and Nakamura, H. (2016) Comparison between Fast Fourier Transform and Autoregressive Model on Analysis of Autonomic Nervous Function after Food Intake in Women. Health, 8, 567574. http://dx.doi.org/10.4236/health.2016.86060 
Keywords

Heart Rate Variability, Power Spectral Analysis, Food Intake, Females, Menstrual Cycle

\section{Introduction}

Stress is known to affect cardiovascular changes, which are usually related to autonomic nervous system activity changes [1]. Spectral analysis of heart rate variability (HRV) provides a sensitive, non-invasive measure of cardiac autonomic regulation, and HRV is acknowledged as a useful tool to estimate autonomic function [2]. Two main frequency components of HRV have been demonstrated: low frequency (LF: $0.04-0.15 \mathrm{~Hz}$ ), reflecting both sympathetic and parasympathetic nervous system activity, and high frequency (HF: $0.15-0.40 \mathrm{~Hz}$ ), reflecting the activity of the parasympathetic nervous system [2]. Consequently, the LF/HF ratio represents the sympathovagal balance [2].

In a frequency domain analysis of HRV, two spectral methods are usually used: the fast Fourier transform (FFT) [3] and the autoregressive model (AR) [4] [5]. Recent studies showed that FFT and AR spectral estimation methods do not lead to equal results [6]-[8]. In addition, to date, there are few reports on whether FFT and AR data processing of HRV after food intake provides similar results. The frequency resolution is in inverse proportion to the temporal resolution in FFT [9]. Therefore, it is postulated that the frequency resolution in FFT diminishes in short-time analysis and discordance occurs between FFT and AR.

In the present study, we applied both FFT and AR spectral analysis after food intake in the follicular and luteal phases and compared raw LF and HF powers, and LF/HF obtained with the two methods.

\section{Methods}

\subsection{Participants}

The subjects were seven healthy female students with body mass index (BMI) $<25 \mathrm{~kg} / \mathrm{m}^{2}$ (not overweight or obese). The inclusion criteria were female gender and age of 20 to 24 years. The exclusion criteria were past and current smoking, alcoholism, high-performance athletes, medication use, oral contraceptive use, irregularity of menstrual cycle, parity, and body mass index $\geq 25 \mathrm{~kg} / \mathrm{m}^{2}$. All subjects were carefully informed about the purpose and potential risks of this experiment, and all gave written informed consent to participate. The study protocol was approved by the Human Ethics Committee of the Graduate School of Human Development and Environment, Kobe University in 2012.

\subsection{Experimental Procedures}

The experiments were conducted from 2012 to 2014. All subjects participated in two sessions according to a randomized crossover design. In the first session, the subjects were randomly assigned to: 1) follicular phase session or 2) luteal phase session. If the first session was conducted in the follicular phase, the second session was conducted in the luteal phase in the same menstrual cycle. If the first session was conducted in the luteal phase, the second session was conducted in the follicular phase in the next menstrual cycle. Participants were determined as being in the follicular or luteal phase based on the occurrence of menstruation and ovulation. Ovulation was recognized by a surge in luteinizing hormone detected using two self-examination kits for luteinizing hormone (L-check FT; Nipro Co., Ltd, Osaka, Japan and P-check; Mizuho Medy Co., Ltd, Saga, Japan).

On the day before testing, the subjects finished their meals by 21:00 $\mathrm{h}$ and went to sleep before 24:00 $\mathrm{h}$. They abstained from drinks containing caffeine, food containing capsaicin, alcohol, and sports activity for $24 \mathrm{~h}$ prior to each testing day. After overnight fasting, each subject arrived at the laboratory between 08:00 $\mathrm{h}$ and 08:30 h and rested in the supine position for $20 \mathrm{~min}$ in an environmentally controlled room (temperature, $23^{\circ} \mathrm{C}-26^{\circ} \mathrm{C}$; relative humidity, $50 \%-60 \%$ ). A test meal was served for the meal intake trial at $09: 50 \mathrm{~h}$, and the subjects finished eating by 10:05 $\mathrm{h}$. The R-R intervals, the time interval between two consecutive $\mathrm{R}$ waves in the electrocardiogram, were continuously recorded before and after meals using an ambulatory electrocardiograph monitor (Active Tracer AC-301A; GMS Inc., Tokyo, Japan) with a sampling rate of $1 \mathrm{kHz}$. The test meal contained 395 kcal of energy, $15.5 \mathrm{~g}$ of protein, $11.3 \mathrm{~g}$ of fat, $57.5 \mathrm{~g}$ of carbohydrate (energy \%: protein/carbohydrate/fat 


\subsection{Heart Rate Variability}

Power spectral analysis of HRV was performed using a fast Fourier transform and 16th-order autoregressive model [10] by Kubios HRV analysis software 2.0 (Biomedical Signal and Medical Imaging Analysis Group, Department of Applied Physics, University of Kuopio, Finland) [11].

We analyzed low-frequency power (LF: $0.04-0.15 \mathrm{~Hz}$ ) and high-frequency power (HF: $0.15-0.40 \mathrm{~Hz}$ ) as HRV parameters before meal intake and at 20,40, 60 and 80 min after meal intake. LF power reflects sympathetic and parasympathetic modulation of the heart, whereas HF power primarily reflects parasympathetic modulation of the heart [2]. LF and HF power were computed for each $30 \mathrm{sec}, 1 \mathrm{~min}, 2.5 \mathrm{~min}$, and $5 \mathrm{~min}$ of the 5 -min R-R data. The LF/HF ratio was calculated as an index of sympathovagal balance [2]. The mean of each 30-sec, 1-min, 2.5-min, and 5-min HRV was used for statistical analysis.

\subsection{Data Analysis}

Reliability was analyzed using the intra-class correlation coefficient (ICC), classifying the values as low (ICC < 0.40 ), good (ICC $=0.40$ to 0.75 ), and excellent (ICC > 0.75) [12]. Bland-Altman plots were drawn to look at the agreement between AR and FFT. The statistical level for significance was established at 0.05 . Statistical analysis was performed using SPSS ${ }^{\circledR} 22.0 \mathrm{~J}$ for Windows (IBM Inc., Tokyo, Japan).

\section{Results}

The mean height, body weight, and BMI of the participants were $157.9 \pm 5.3 \mathrm{~cm}, 52.0 \pm 6.1 \mathrm{~kg}$, and $20.9 \pm 2.2$ $\mathrm{kg} / \mathrm{m}^{2}$, respectively.

Results of ICC in LF are shown in Table 1. In $30 \mathrm{~s}$ segment of analysis, an excellent correlation (ICC $>0.75$ ) was found $60 \mathrm{~min}$ after meal intake in the follicular phase and $20 \mathrm{~min}$ after meal intake in the luteal phase. In 1 min segment of analysis, an excellent correlation was found before meal intake and 20 and 60 min after meal intake in the follicular phase, and 20 and $80 \mathrm{~min}$ after luteal phase. In $2.5 \mathrm{~min}$ segment of analysis, an excellent correlation was found at all time points in both phases except 40 min after meal intake in luteal phase. In 5 min segment analysis, an excellent correlation was found at all time points in both phases.

Results of ICC in HF are shown in Table 2. In $30 \mathrm{~s}$ segment of analysis, there was no excellent correlation. In $1 \mathrm{~min}$ segment of analysis, an excellent correlation was found 40 and $60 \mathrm{~min}$ after meal intake in the follicular phase and in 20, 40, 60, and 80 min after meal intake in the luteal phase. In $2.5 \mathrm{~min}$ segment of analysis, an excellent correlation was found at all time points except $20 \mathrm{~min}$ after meal intake in the follicular phase. In $5 \mathrm{~min}$ segment of analysis, an excellent correlation was found at all time points in both phases.

Results of the ICC for LF/HF ratio are shown in Table 3. In $30 \mathrm{~s}$ segment of analysis, there was no excellent correlation found. In 1 min segment of analysis, an excellent correlation was found 40 min after meal intake in the follicular phase and before meal intake and 20 and $80 \mathrm{~min}$ after meal intake in the luteal phase. In $2.5 \mathrm{~min}$ segment of analysis, an excellent correlation was found 20,40,60, and 80 min after meal intake in the follicular phase and $20 \mathrm{~min}$ after meal intake in the luteal phase. In 5 min segment of analysis, an excellent correlation was found before meal intake and 20,40, and 60 min after meal intake in the follicular phase and 20, 60, and 80 min after meal intake in the luteal phase.

Results of Bland and Altman analysis in LF, HF, and LF/HF ratio are shown in Tables 1-3, respectively. In terms of agreement between FFT and AR, broad 95\% level of agreement was found in $30 \mathrm{~s}$ of segment analysis compared with $2.5 \mathrm{~min}$ or $5 \mathrm{~min}$ of segment analysis in LF, HF, and LF/HF ratio.

\section{Discussion}

FFT and AR are mainly used in the context of short-term HRV signals. In the present study, within $30 \mathrm{~s}$ and 1 min segments, many of the data showed little interchangeability between FFT and AR in LF, HF, and LF/HF ratio in both the follicular and luteal phases. In 2.5 or $5 \mathrm{~min}$ of segment analysis, many of the data showed interchangeability between FFT and AR in LF and HF, but not in LF/HF ratio in the follicular or luteal phases. Additionally, FFT underestimated HRV compared with AR, and the extent of underestimation increased with increasing AR value. These data show that the agreement increases according to the length of analysis segment, 
Table 1. Intra-class coefficient, bias, and limits of agreements of the differences in low frequency between fast Fourier transform and autoregressive model.

\begin{tabular}{|c|c|c|c|c|}
\hline & \multicolumn{2}{|c|}{ Follicular phase } & \multicolumn{2}{|c|}{ Luteal phase } \\
\hline & $\operatorname{ICC}(95 \% \mathrm{CI})$ & $\begin{array}{l}\text { Bland Altman } \\
\text { Bias (95\% LoA) }\end{array}$ & $\operatorname{ICC}(95 \% \mathrm{CI})$ & $\begin{array}{c}\text { Bland Altman } \\
\text { Bias }(95 \% \text { LoA })\end{array}$ \\
\hline \multicolumn{5}{|c|}{$30 \mathrm{~s}$ segment of analysis } \\
\hline Before & $0.048(-0.188,0.278)$ & $-5142(-54,643,44,358)$ & $0.461(0.255-0.627)$ & $-411(-4514,3692)$ \\
\hline 20 min after & $0.101(-0.135,0.327)$ & $-5961(-96,237,84,315)$ & $0.792(0.685-0.865)^{*}$ & $-392(-2840,2055)$ \\
\hline 40 min after & $0.136(-0.101,0.358)$ & $-2227(-49,733,45,278)$ & $0.660(0.504-0.774)$ & $-743(-5918,4432)$ \\
\hline 60 min after & $0.872(0.802,0.919)^{*}$ & $236(-3535,4006)$ & $0.032(-0.203-0.264)$ & $-1105(-17,476,15,266)$ \\
\hline 80 min after & $0.164(-0.072,0.383)$ & $-1171(-24,126,21,784)$ & $0.727(0.595-0.821)$ & $-232(-2383,1919)$ \\
\hline \multicolumn{5}{|c|}{1 min segment of analysis } \\
\hline Before & $0.813(0.661-0.901)^{*}$ & $430(-3956,4816)$ & $0.676(0.447-0.822)$ & $-40(-3313,3233)$ \\
\hline 20 min after & $0.803(0.643-0.895)^{*}$ & $-452(-6248,5346)$ & $0.791(0.625-0.889)^{*}$ & $466(-3260,4192)$ \\
\hline 40 min after & $0.701(0.483-0.837)$ & $-514(-6323,5296)$ & $0.649(0.407-0.806)$ & $0(-3098,3098)$ \\
\hline $60 \mathrm{~min}$ after & $0.952(0.907-0.975)^{*}$ & $0.1(-2035,2035)$ & $0.613(0.356-0.784)$ & $-107(-2318,2105)$ \\
\hline 80 min after & $0.712(0.478-0.852)$ & $12(-2229,2253)$ & $0.873(0.764-0.934)^{*}$ & $127(-1619,1873)$ \\
\hline \multicolumn{5}{|c|}{2.5 min segment of analysis } \\
\hline Before & $0.943(0.832-0.981)^{*}$ & $-15(-2029,1999)$ & $0.898(0.713-0.966)^{*}$ & $76(-1204,1357)$ \\
\hline 20 min after & $0.939(0.822-0.980)^{*}$ & $189(-2786,3163)$ & $0.974(0.920-0.992)^{*}$ & $292(-606,1190)$ \\
\hline 40 min after & $0.890(0.692-0.963)^{*}$ & $430(-4590,5450)$ & $0.728(0.341-0.904)$ & $533(-2363,3428)$ \\
\hline 60 min after & $0.987(0.959-0.996)^{*}$ & $-115(-989,758)$ & $0.801(0.487-0.931)^{*}$ & $134(-782,1050)$ \\
\hline 80 min after & $0.979(0.935-0.993)^{*}$ & $-246(-995,502)$ & $0.937(0.817-0.980)^{*}$ & $-43(-779,694)$ \\
\hline \multicolumn{5}{|c|}{5 min segment of analysis } \\
\hline Before & $0.996(0.977-0.999)^{*}$ & $-189(-524,147)$ & $0.980(0.888-0.997)^{*}$ & $-99(-567,370)$ \\
\hline 20 min after & $0.899(0.526-0.982)^{*}$ & $-241(-2944,2463)$ & $0.991(0.948-0.998)^{*}$ & $-27(-543,490)$ \\
\hline 40 min after & $0.996(0.973-0.999)^{*}$ & $-236(-1132,660)$ & $0.860(0.391-0.975)^{*}$ & $-155(-1245,935)$ \\
\hline 60 min after & $0.985(0.916-0.997)^{*}$ & $213(-976,1403)$ & $0.923(0.623-0.986)^{*}$ & $184(-311,679)$ \\
\hline 80 min after & $0.987(0.927-0.998)^{*}$ & $-243(-863,376)$ & $0.974(0.856-0.995)^{*}$ & $10(-477.2,496.9)$ \\
\hline
\end{tabular}

Before, before food intake; $20 \mathrm{~min}$ after, $20 \mathrm{~min}$ after food intake; $40 \mathrm{~min}$ after, $40 \mathrm{~min}$ after food intake; $60 \mathrm{~min}$ after, $60 \mathrm{~min}$ after food intake; $80 \mathrm{~min}$ after, $80 \mathrm{~min}$ after food intake; "ICC > 0.75; ICC, intra-class coefficient; CI, confidence interval; LoA, limit of agreement.

indicating no interchangeability in short length of analysis segment. In previous studies, comparisons between FFT and AR were conducted during exercise [13] [14] in patients with hypertension [15], in patients with diabetes [16], and in subjects performing orthostatic [8] or tilt tests [7]. The results of these studies showed discordance between FFT and AR. However, there is little evidence on interchangeability of FFT and AR in meal intake condition. Pivik et al. reported that LF/HF decreased after $340 \mathrm{kcal}$ of meal intake in children, in which FFT was used for power spectral analysis of 3-min segments [17]. Conversely, Pivik et al. reported that LF/HF increased after $340 \mathrm{kcal}$ of meal intake in another experiment, in which FFT was also used for analysis of 3-min 
Table 2. Intra-class coefficient, bias, and limits of agreements of the differences in high frequency between fast Fourier transform and autoregressive model.

\begin{tabular}{|c|c|c|c|c|}
\hline & \multicolumn{2}{|c|}{ Follicular phase } & \multicolumn{2}{|c|}{ Luteal phase } \\
\hline & $\operatorname{ICC}(95 \% \mathrm{CI})$ & $\begin{array}{l}\text { Bland Altman } \\
\text { Bias (95\% LoA) }\end{array}$ & $\operatorname{ICC}(95 \% \mathrm{CI})$ & $\begin{array}{l}\text { Bland Altman } \\
\text { Bias (95\% LoA) }\end{array}$ \\
\hline \multicolumn{5}{|c|}{$30 \mathrm{~s}$ segment of analysis } \\
\hline Before & $0.006(-0.228-0.239)$ & $-5850(-49,050,37,349)$ & $0.101(-0.223-0.244)$ & $-21986(-245,683,201,712)$ \\
\hline 20 min after & $0.505(0.308-0.661)$ & $-990(-7385,5406)$ & $0.566(0.383-0.706)$ & $-594(-4061,2874)$ \\
\hline 40 min after & $0.137(-0.100-0.359)$ & $-1209(-13,578,11,160)$ & $0.101(-0.136-0.326)$ & $-1154(-7865,5556)$ \\
\hline 60 min after & $0.303(0.075-0.501)$ & $-698(-4144,2748)$ & $0.085(-0.151-0.313)$ & $-1102(-7853,5649)$ \\
\hline 80 min after & $0.001(-0.232-0.235)$ & $\begin{array}{c}-8514(-132,440 \\
115,412)\end{array}$ & $0.145(-0.091-0.367)$ & $-871(-6348,4606)$ \\
\hline \multicolumn{5}{|c|}{1 min segment of analysis } \\
\hline Before & $0.165(-0.173-0.469)$ & $-1811(-17,764,14,142)$ & $0.336(0.007-0.599)$ & $-1334(-11,094,8425)$ \\
\hline 20 min after & $0.686(0.460-0.828)$ & $-266(-2074,1543)$ & $0.934(0.873-0.966)^{*}$ & $-12(-1167,1144)$ \\
\hline 40 min after & $0.801(0.642-0.895)^{*}$ & $-176(-1926,1573)$ & $0.814(0.662-0.902)^{*}$ & $-326(-1520,867)$ \\
\hline 60 min after & $0.899(0.810-0.948)^{*}$ & $-85(-839,670)$ & $0.940(0.885-0.969)^{*}$ & $-20(-462,423)$ \\
\hline 80 min after & $0.743(0.548-0.862)$ & $-91(-909,727)$ & $0.970(0.942-0.985)^{*}$ & $-23(-271,224)$ \\
\hline \multicolumn{5}{|c|}{$2.5 \mathrm{~min}$ segment of analysis } \\
\hline Before & $0.963(0.888-0.988)^{*}$ & $-376(-1514,762)$ & $0.988(0.964-0.966)^{*}$ & $-100(-828,628)$ \\
\hline 20 min after & $0.730(0.346-0.905)$ & $-244(-1736,1248)$ & $0.997(0.991-0.999)^{*}$ & $7(-196,211)$ \\
\hline 40 min after & $0.945(0.839-0.982)^{*}$ & $-25(-982,931)$ & $0.989(0.965-0.966)^{*}$ & $-16(-249,218)$ \\
\hline $60 \mathrm{~min}$ after & $0.932(0.804-0.978)^{*}$ & $-64(-592,463)$ & $0.916(0.761-0.972)^{*}$ & $-22(-521,476)$ \\
\hline 80 min after & $0.955(0.866-0.985)^{*}$ & $-76(-475,323)$ & $0.976(0.927-0.992)^{*}$ & $-33(-248,183)$ \\
\hline \multicolumn{5}{|c|}{5 min segment of analysis } \\
\hline Before & $0.949(0.737-0.991)^{*}$ & $-374(-1241,493)$ & $0.997(0.980-0.999)^{*}$ & $-73(-475,328)$ \\
\hline 20 min after & $0.909(0.565-0.984)^{*}$ & $-100(-711,512)$ & $0.980(0.887-0.997)^{*}$ & $-133(-631,365)$ \\
\hline 40 min after & $0.948(0.730-0.991)^{*}$ & $-155(-946,637)$ & $0.978(0.880-0.996)^{*}$ & $78(-293,448)$ \\
\hline 60 min after & $0.981(0.892-0.997)^{*}$ & $-35(-305,235)$ & $0.989(0.939-0.998)^{*}$ & $36(-143,215)$ \\
\hline 80 min after & $0.860(0.392-0.975)^{*}$ & $-182(-796,432)$ & $0.986(0.920-0.998)^{*}$ & $-3(-180,174)$ \\
\hline
\end{tabular}

Before, before food intake; $20 \mathrm{~min}$ after, $20 \mathrm{~min}$ after food intake; $40 \mathrm{~min}$ after, $40 \mathrm{~min}$ after food intake; $60 \mathrm{~min}$ after, $60 \mathrm{~min}$ after food intake;

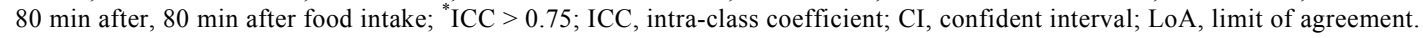

segments [18]. This indicates that FFT results are unstable in 3-min analysis segments in food intake condition, although both experiments were conducted by the same researchers using the same protocol. Also, these results indicate that signals of HRV in meal intake may be non-stationary. The underlying mechanism of these results is unclear. FFT uses a window function for spectral analysis. However, the frequency resolution is in inverse proportion to the temporal resolution in FFT [9], which may involve discordance between FFT and AR in shorttime analysis.

There are some limitations to be considered. First, the number of participants was relatively small. Second, 
Table 3. Intra-class coefficient, bias, and limits of agreements of the differences in low frequency/high frequency ratio between fast Fourier transform and autoregressive model.

\begin{tabular}{|c|c|c|c|c|}
\hline & \multicolumn{2}{|c|}{ Follicular phase } & \multicolumn{2}{|c|}{ Luteal phase } \\
\hline & ICC $(95 \% \mathrm{CI})$ & $\begin{array}{c}\text { Bland Altman } \\
\text { Bias (95\% LoA) }\end{array}$ & ICC $(95 \% \mathrm{CI})$ & $\begin{array}{c}\text { Bland Altman } \\
\text { Bias (95\% LoA) }\end{array}$ \\
\hline \multicolumn{5}{|c|}{$30 \mathrm{~s}$ segment of analysis } \\
\hline Before & $0.142(-0.094-0.364)$ & $-1.527(-19.756,16.703)$ & $0.514(0.318-0.667)$ & $0.427(-2.434,3.288)$ \\
\hline 20 min after & $0.634(0.470-0.756)$ & $0.025(-4.342,4.392)$ & $0.668(0.515-0.780)$ & $0.878(-6.124,7.880)$ \\
\hline 40 min after & $0.631(0.466-0.753)$ & $0.009(-2.931,2.949)$ & $0.522(0.329-0.674)$ & $0.275(-3.469,4.020)$ \\
\hline $60 \mathrm{~min}$ after & $0.651(0.492-0.768)$ & $0.564(-3.203,4.331)$ & $0.188(-0.048-0.404)$ & $-0.441(-9.800,8.918)$ \\
\hline 80 min after & $0.359(0.137-0.547)$ & $-0.406(-12.038,11.225)$ & $0.609(0.438-0.738)$ & $0.695(-6.040,7.430)$ \\
\hline \multicolumn{5}{|c|}{1 min segment of analysis } \\
\hline Before & $0.493(0.195-0.707)$ & $0.450(-1.953,2.853)$ & $0.778(0.604-0.882)^{*}$ & $0.112(-1.358,1.594)$ \\
\hline 20 min after & $0.746(0.553-0.863)$ & $0.401(-2.286,3.100)$ & $0.844(0.713-0.918)^{*}$ & $0.145(-2.608,2.897)$ \\
\hline 40 min after & $0.788(0.619-0887)^{*}$ & $0.133(-1.701,1.966)$ & $0.461(0.155-0686)$ & $0.069(-2.832,2.970)$ \\
\hline $60 \mathrm{~min}$ after & $0.661(0.424-0.813)$ & $0.023(-2.079,2.126)$ & $0.733(0.532-0.856)$ & $0.110(-1.287,1.508)$ \\
\hline 80 min after & $0.642(0.397-0.802)$ & $0.415(-4.156,4.986)$ & $0.758(0.572-0.870)^{*}$ & $0.563(-3.811,4.937)$ \\
\hline \multicolumn{5}{|c|}{2.5 min segment of analysis } \\
\hline Before & $0.748(0.380-0.911)$ & $0.055(-0.788,0.897)$ & $0.623(0.160-0.861)$ & $-0.093(-1.132,0.945)$ \\
\hline 20 min after & $0.939(0.831-0.980)^{*}$ & $0.080(-0.869,1.030)$ & $0.788(0.461-0.927)^{*}$ & $0.835(-2.108,3.779)$ \\
\hline 40 min after & $0.877(0.660-0959)^{*}$ & $0.314(-0.712,1.339)$ & $0.717(0.322-0.900)$ & $0.233(-1.444,1.910)$ \\
\hline 60 min after & $0.779(0.442-0.923)^{*}$ & $0.098(-1.175,1.371)$ & $0.737(0.358-0.907)$ & $0.018(-0.840,0.876)$ \\
\hline 80 min after & $0.809(0.505-0.934)^{*}$ & $-0.160(-1.252,0.933)$ & $0.743(0.370-0.910)$ & $0.385(-3.232,4.003)$ \\
\hline \multicolumn{5}{|c|}{5 min segment of analysis } \\
\hline Before & $0.929(0.646-0.987)^{*}$ & $-0.037(-0.490,0.416)$ & $0.565(-0.236-0.909)$ & $0.238(-1.056,1.532)$ \\
\hline 20 min after & $0.881(0.461-0.978)^{*}$ & $0.329(-1.094,1.752)$ & $0.977(0.875-0.996)^{*}$ & $-0.080(-0.850,0.690)$ \\
\hline 40 min after & $0.876(0.445-0.978)^{*}$ & $0.329(-0.818,0.911)$ & $0.613(-0.166-0.921)$ & $-0.152(-1.529,1.225)$ \\
\hline 60 min after & $0.916(0.591-0.985)^{*}$ & $0.260(-0.608,1.128)$ & $0.857(0.379-0.974)^{*}$ & $0.327(-0.443,1.097)$ \\
\hline 80 min after & $0.732(0.051-0.948)$ & $0.340(-1.606,2.287)$ & $0.946(0.720-0.990)^{*}$ & $0.079(-1.045,1.203)$ \\
\hline
\end{tabular}

Before, before food intake; $20 \mathrm{~min}$ after, $20 \mathrm{~min}$ after food intake; $40 \mathrm{~min}$ after, $40 \mathrm{~min}$ after food intake; $60 \mathrm{~min}$ after, $60 \mathrm{~min}$ after food intake; $80 \mathrm{~min}$ after, $80 \mathrm{~min}$ after food intake; " ICC > 0.75; ICC, intra-class coefficient; CI, confidence interval; LoA, limit of agreement.

the present results were provided by only one test meal. In the present study, we validated the hypothesis that the discordance occurs between FFT and AR in short-time analysis, despite the small number of participants and the present test meal. However, the further study should be conducted in large number of participants or by variable patterns of meal.

\section{Conclusion}

In conclusion, FFT correlated poorly with AR when the length of the analysis segment was shortened. Additionally, FFT underestimated HRV compared with AR, and the extent of underestimation increased with increasing AR value.

\section{Acknowledgements}

The authors thank the participants of the study. A part of the research study was supported by a Grant-in-Aid for 
JSPS Fellows No. 13J02216.

\section{Conflict of Interest}

The author reports no conflicts of interest in this work.

\section{References}

[1] Rozanski, A., Bairey, C.N., Krantz, D.S., Friedman, J., Resser, K.J., Morell, M., Hilton-Chalfen, S., Hestrin, L., Bietendorf, J. and Berman, D.S. (1988) Mental Stress and the Induction of Silent Myocardial Ischemia in Patients with Coronary Artery Disease. The New England Journal of Medicine, 318, 1005-1012. http://dx.doi.org/10.1056/NEJM198804213181601

[2] Task Force of the European Society of Cardiology and the North American Society of Pacing and Electrophysiology. Heart Rate Variability (1996) Standards of Measurement, Physiological Interpretation, and Clinical Use. Task Force of the European Society of Cardiology and the North American Society of Pacing and Electrophysiology. European Heart Journal, 17, 354-381.

[3] Akselrod, S., Gordon, D., Ubel, F.A., Shannon, D.C., Berger, A.C. and Cohen, R.J. (1981) Power Spectrum Analysis of Heart Rate Fluctuation: A Quantitative Probe of Beat-to-Beat Cardiovascular Control. Science, 213, 220-222. http://dx.doi.org/10.1126/science.6166045

[4] Malliani, A., Pagani, M., Lombardi, F. and Cerutti, S. (1991) Cardiovascular Neural Regulation Explored in the Frequency Domain. Circulation, 84, 482-492. http://dx.doi.org/10.1161/01.CIR.84.2.482

[5] Pagani, M., Lombardi, F., Guzzetti, S., Rimoldi, O., Furlan, R., Pizzinelli, P., Sandrone, G., Malfatto, G., Dell'Orto, S. and Piccaluga, E. (1986) Power Spectral Analysis of Heart Rate and Arterial Pressure Variabilities as a Marker of Sympatho-Vagal Interaction in Man and Conscious Dog. Circulation Research, 59, 178-193. http://dx.doi.org/10.1161/01.RES.59.2.178

[6] Giambastiani, B.M.S. (2007) Evoluzione Idrologica ed Idrogeologica Della Pineta di san Vitale (Ravenna). PhD Thesis, Bologna University, Bologna.

[7] Badilini, F., Maison-Blanche, P. and Coumel, P. (1998) Heart Rate Variability in Passive Tilt Test: Comparative Evaluation of Autoregressive and FFT Spectral Analyses. Pacing and Clinical Electrophysiology, 21, 1122-1132. http://dx.doi.org/10.1111/j.1540-8159.1998.tb00159.x

[8] Pichon, A., Roulaud, M., Antoine-Jonville, S., de Bisschop, C. and Denjean, A. (2006) Spectral Analysis of Heart Rate Variability: Interchangeability between Autoregressive Analysis and Fast Fourier Transform. Journal of Electrocardiology, 39, 31-37. http://dx.doi.org/10.1016/j.jelectrocard.2005.08.001

[9] Freeman, J.W. and Maurer, K. (1989) Advances in Brain Theory Give New Directions to the Use of the Technologies of Brain Mapping in Behavioral Studies. In: Maurer, K., Ed., Topographic Brain Mapping of EEG and Evoked Potentials, Springer-Verlag, Berlin, 118-126. http://dx.doi.org/10.1007/978-3-642-72658-3_7

[10] Boardman, A., Schlindwein, F.S., Rocha, A.P. and Leite, A. (2002) A Study on the Optimum Order of Autoregressive Models for Heart Rate variability. Physiological Measurement, 23, 325-336. http://dx.doi.org/10.1088/0967-3334/23/2/308

[11] Niskanen, J.P., Tarvainen, M.P., Ranta-Aho, P.O. and Karjalainen, P.A. (2004) Software for Advanced HRV Analysis. Computer Methods and Programs in Biomedicine, 76, 73-81. http://dx.doi.org/10.1016/j.cmpb.2004.03.004

[12] Fleiss, J.L. (1986) The Design and Analysis of Clinical Experiments. John Wiley Sons, New York.

[13] Mendonca, G.V., Fernhall, B., Heffernan, K.S. and Pereira, F.D. (2009) Spectral Methods of Heart Rate Variability Analysis during Dynamic Exercise. Clinical Autonomic Research, 19, 237-245. http://dx.doi.org/10.1007/s10286-009-0018-1

[14] Weippert, M., Kumar, M., Kreuzfeld, S., Arndt, D., Rieger, A. and Stoll, R. (2010) Comparison of Three Mobile Devices for Measuring R-R Intervals and Heart Rate Variability: Polar S810i, Suunto t6 and an Ambulatory ECG System. European Journal of Applied Physiology, 109, 779-786. http://dx.doi.org/10.1007/s00421-010-1415-9

[15] Silva, G.J., Ushizima, M.R., Lessa, P.S., Cardoso, L., Drager, L.F., Atala, M.M., Consolim-Colombo, F.M., .Lopes, H.F., Cestari, I.A., Krieger, J.E. and Krieger, E.M. (2009) Critical Analysis of Autoregressive and Fast Fourier Transform Markers of Cardiovascular Variability in Rats and Humans. Brazilian Journal of Medical and Biological Research, 42, 386-396. http://dx.doi.org/10.1590/S0100-879X2009000400012

[16] Chemla, D., Young, J., Badilini, F., Maison-Blanche, P., Affres, H., Lecarpentier, Y. and Chanson, P. (2005) Comparison of Fast Fourier Transform and Autoregressive Spectral Analysis for the Study of Heart Rate Variability in Diabetic Patients. International Journal of Cardiology, 104, 307-313. http://dx.doi.org/10.1016/j.ijcard.2004.12.018

[17] Pivik, R.T. and Dykman, R.A. (2004) Cardiovascular Effects of Morning Nutrition in Preadolescents. Physiology \& 
Behavior, 82, 295-302. http://dx.doi.org/10.1016/j.physbeh.2004.03.016

[18] Pivik, R.T., Dykman, R.A., Tennal, K. and Gu, Y. (2006) Skipping Breakfast: Gender Effects on Resting Heart Rate Measures in Preadolescents. Physiology \& Behavior, 89, 270-280. http://dx.doi.org/10.1016/j.physbeh.2006.06.001 